\title{
ESTÉTICA DE LA REPETICIÓN
}

Lydia Elizalde*

RESUMEN: Se ensayan una serie de reflexiones en torno a la estética de la repetición, a partir de las ideas de Calabrese en cuanto a los fenómenos de producción de objetos de arte contemporáneos y a su valor, enfrentado todo ello a una estética de la singularidad y originalidad.

Palabras Clave: estética, repetición, Benjamin, Calabrese, Lichtenstein.
ABSTRACT: In this article, we will reflect on the aesthetics of repetition by means of Calabrese's ideas regarding the phenomenon of the production of contemporary art objects as well as their value in juxtaposition with the aesthetics of singularity and originality.

KEYWORDS: aesthetics, repetition, Benjamin, Calabrese, Lichtenstein.

RECEPCIÓN: 26 de abril de 2012.

ACEPTACIÓN: 20 de noviembre de 2012.

* Teorías y crítica del arte, Facultad de Artes-UAEM. 


\section{ESTÉTICA DE LA REPETICIÓN}

C

on la finalidad de revisar el razonamiento promovido por el idealismo y aún después de las vanguardias históricas, que establecían como valor de la obra de arte lo irrepetible y original, presento las reflexiones realizadas por Omar Calabrese sobre la estética de la repetición para calificar los fenómenos de producción de objetos artísticos contemporáneos; mismas que se suman a las argumentaciones que años antes había realizado Walter Benjamin con respecto al valor de exhibición de la obra de arte.

Calabrese señala que la unicidad de la obra de arte fue derribada por las reproducciones artísticas desde los años 60 y expone la práctica de una estética de la repetición y de la variación que, en la posmodernidad, supe- ra la idealización de la originalidad de la obra de arte. La repetición se comprende desde la seriación hasta las representaciones en el hipertexto, que incluyen diferentes géneros expresivos y en los que se insertan la cita, la traducción, el pastiche, el collage o montaje, dependiendo del medio.

Argumenta el semiólogo que actualmente existe una conciencia de que todo es repetible, que lo importante estéticamente no es la originalidad de la obra, sino su fruición, su gusto, y éste lo define el emisor -artista plástico, visual, escritordesde la construcción del hipertexto y se presenta en diferentes modalidades, para poner en juego el sentido último que consumirá e interpretará el receptor. 


\section{Teorías estéticas de Benjamin}

El origen de estas reflexiones en torno a la repetición y exhibición de la obra de arte las inicia Walter Benjamin en la década de los años treinta. En 1936 publica el texto La obra de arte en la época de su reproductibilidad técnica, en donde hace una argumentación sobre las características de reproducción del objeto de arte, exponiendo que éste puede ser rehecho o imitado.

Expone que la reproducción técnica del arte se ha impuesto a lo largo de la historia y con una intensidad creciente. ${ }^{1}$ Las técnicas de reproducción de imágenes por medio de la litografía fueron superadas por la reproducción fotográfica, sustituyendo la reproducción de imágenes con la mano, por el ojo. De la litografía surge la revista ilustrada y de la fotografía el cine. ${ }^{2}$

Las técnicas que trata Benjamin en este texto son básicamente la litografía (en las revistas ilustradas), las grabaciones de música, la fotografía y el cine sonoro, modificando el concepto de autenticidad del original, contenido por el aquí y ahora. ${ }^{3}$

${ }^{1}$ Walter Benjamin, La obra de arte en la época de su reproductibilidad técnica, 2003, México, Itaca, traducción de Andrés E. Weikert, introducción de Bolívar Echeverría, p. 39.

${ }^{2}$ Op. cit., p. 40.

${ }^{3}$ Ibid., p. 41.
Benjamin continúa su argumentación: "Mientras lo auténtico mantiene su plena autoridad frente a la reproducción manual, a la que por lo regular se califica de falsificación, no puede hacerlo en cambio frente a la reproducción técnica". ${ }^{4}$ Ésta hace más independiente el original que la reproducción manual.

Sobre esto, expresa:

La técnica de reproducción, se puede formular en general, separa a lo reproducido del ámbito de la tradición. Al multiplicar sus reproducciones, pone, en lugar de su aparición única, su aparición masiva. Y al permitir que la reproducción se aproxime al receptor en su situación singular actualiza lo reproducido. Y esta segmentación se relaciona con la crisis y renovación contemporánea de la cultura. $^{5}$

El acelerado desarrollo de diversas técnicas y su aplicación para la reproducción de objetos artísticos, desde mediados del siglo XX, ha modificado la relación de percepción sensorial y consumo por parte del receptor.

De esta manera, Benjamin habla de la destrucción del aura de la obra de arte que el filósofo define como un entretejido de espacio y tiempo, un aparecimiento único en donde rela-

${ }^{4}$ Ibid., p. 43.

${ }^{5}$ Ibid., p. 44-5. 
NOTAS

ciona los objetos históricos con el concepto de un valor o momento propio de los objetos naturales. ${ }^{6}$

La demanda de las masas contemporáneas de "acercarse las cosas", la necesidad de apoderarse del objeto en su más próxima cercanía, pero en imagen, y más aún en copia, en reproducción, extrae el objeto de arte fuera de su cobertura, demuele el aura para incrementar el campo de lo visible. $^{7}$

Al valor aureático del original de la obra de arte, se añade el valor de exhibición por su extensión en la seriación y en la repetición mediática en objetos artísticos en los que inciden los cambios tecnológicos como son grabaciones de música, el cine, la fotografía y reproducciones impresas de obras artísticas.

176 Desde la formulación de una teoría estética presenta una hermenéutica crítica en donde vincula la noción de estética desde la percepción sensorial con los modos de significación. Esta recepción estética es resultado de los cambios en los modos de percepción sensorial. Benjamin expresa que, dentro de largos periodos históricos, junto con el modo de existencia de los colectivos humanos, se transforma también la manera de su recepción sensorial. ${ }^{8}$

${ }^{6}$ Ibid., p. 47.

${ }^{7}$ Ibid., p. 48.

${ }^{8}$ Ibid., p. 47.
Reflexiona sobre los cambios que se producen en el arte, en la reproducción masiva y señala que incluso en la reproducción mejor acabada falta algo: la experiencia de su hechura, es decir su aura, las características que la hacen única e irrepetible. ${ }^{9}$

El desarrollo de la reproducción masiva cambia el ámbito del arte, genera una diferencia en la percepción corporal, matérica. ${ }^{10}$ Señala Benjamin que este hecho puede generar transformaciones sociales. ${ }^{11}$ Destaca que desaparece la función cultural o ritual del arte y aparece su función política, su función social en la comunicación de masas. El peso absoluto recae en el valor de exhibición de la obra de arte y ésta se ha convertido en una creación dotada de funciones completamente nuevas, de interconexiones, como es el caso del arte que

${ }^{9}$ Ibid., p 49-50.

${ }^{10} \mathrm{Idem}$.

${ }^{11}$ Algunos teóricos contemporáneos han estudiado los cambios en la percepción y recepción estética, producto de las transformaciones tecnológicas, entre ellos: Umberto Eco, en el texto Apocalípticos e integrados a la cultura masas (1965), expone que la nueva cultura tecnificada y mass mediática que genera los cambios en la sociedad; en el compendio Interpretación y sobreinterpretación (1995) presenta los límites de la recepción estética; Giovanni Sartori en Homo videns (1998) afirma que cuando se sustituye el lenguaje abstracto por el lenguaje perceptivo, concreto, se está empobreciendo nuestra capacidad de entender y, de esta manera, pasamos de homo sapiens a homo videns. Jean Baudrillard, 2001, postula que la sociedad actual, dominada por los ordenadores y máquinas electrónicas convierten la vida en virtualidad. 
se difunde en medios masivos y específicamente en el cine. ${ }^{12}$

\section{Estética del Neobarroco}

En el texto La era neobarroca, Omar Calabrese expone que las transformaciones de los medios han incidido en la recepción estética de los objetos artísticos contemporáneos. La repetición a partir de las soluciones técnicas permite la fácil reproductibilidad de los objetos artísticos, casi a la par de los objetos de uso cotidiano. ${ }^{13}$

Señala que estéticamente lo importante en la obra de arte no es la originalidad de la obra sino su fruición; coincide con esa naturaleza de la información electrónica basada en hipertexto que busca sobre todo poner al lector a jugar y a participar, y que tiene su antecedente en la noción de la doble productividad, según la cual, el autor se empeña en diseñar artefactos y "modelos para armar" y no en mostrar una visión original y novedosa de las cosas -la cual, de otro lado, debe ser formada por el lector y no realizada de antemano por el autor. ${ }^{14}$

Indica que hay incluso una consecuencia adicional: el hipertexto está exigiendo, en su momento creativo, la estructura del diseño; y en su

\footnotetext{
${ }^{12}$ Benjamin, op.cit. p. 54.

${ }^{13}$ Omar Calabrese, La era neobarroca, 1999, Madrid, Cátedra, p. 14.

${ }^{14}$ Ibid., p. 117.
}

recepción, el juego; la estética contemporánea se está vinculando, de alguna manera, con diferentes expresiones de las tendencias artísticas contemporáneas: en música, en instalaciones, en artes visuales, en movimientos que retoman características de los estilos de las vanguardias a los que actualmente les anteponemos el prefijo de neo. ${ }^{15}$

Calabrese detalla:

En los productos de ficción de las actuales comunicaciones de masa [...] los replicantes-films de serie, telefilms, remakes, novelas de consumo, cómics, canciones, otros-, nacen como producto de una mecánica de repetición y optimización del trabajo, pero su perfeccionamiento produce más o menos, involuntariamente, una estética. Exactamente una estética de la repetición. ${ }^{16}$

Umberto Eco apunta en el prólogo del texto de Calabrese que los objetos artísticos y los producidos en los mass media que estudia el semiólogo se relacionan con los procesos, los flujos y las derivas interpretativas (translator: interpretative drifts), que conciernen al conjunto de los mensajes que circulan en el territorio de la comunicación; y la problemática que trata su destacado discípulo concierne a algunas profundas mutaciones culturales que se de-

${ }^{15}$ Op.cit., p. 28.

${ }^{16}$ Ibid., p. 44. 
NOTAS

sarrollaron a partir de las tres últimas décadas del siglo XX. ${ }^{17}$

\section{Pragmática de la repetición}

La estética de la repetición articula varias modalidades que inciden en la expresión de la forma y del contenido: ${ }^{18}$

1. La estandarización • Producción en serie

2. La repetición de la $\bullet$ Diferente del original, pero estructura de un semejante al mismo producto artístico

3. La repetición para $\cdot$ Demanda diferentes tipos $\cdot$ Consolación de consumo $\quad$ Consumo productivo

1. En la estandarización se presenta la repetición como modo de producción de una serie a partir de un prototipo, con una matriz única, con la posibilidad de una producción de diferentes versiones o su continuidad en diferentes medios, con la posibilidad de una producción en serie de las diferentes versiones de una obra plástica, la continuidad, la reintepretación de una propuesta icónica; la variación estructural, como son las continuaciones de las aventuras de los personajes, los recorridos de historias análogas (guiones tipo), la repetición de fragmentos, la repetición de detalles de obras gráficas, plásticas, visuales, espaciales.

${ }^{17}$ Ibid., p. 14.

${ }^{18}$ Ibid., p. 51.
Calabrese también enumera algunas fórmulas de la repetición: el modo icónico que considera la imagen (por ejemplo, del protagonista), el modo temático y el modo narrativo - las variaciones de estructura en el guión tipo o en los motivos recurrentes. ${ }^{19}$

Un ejemplo de la estandarización es el caso de las obras de Roy Lichtenstein sobre las cuales el artista conforma su idiolecto visual. El estudio que ha desarrollado David Barsalou desde 1997, ${ }^{20}$ en el proyecto Deconstructing Roy Lichtenstein, le permitió identificar que la obra plástica del artista del Pop Art se originó a partir de trabajos de jóvenes artistas gráficos que publicaron en comics durante la década de los años sesenta. Barsalou tenía la impresión de que Lichtenstein había utilizado cómics existentes como referencia para su trabajo, pero no tenía idea hasta qué medida se había replicado la fuente original. ${ }^{21}$

Por otro lado, podría resultar incongruente señalar a Lichtenstein por la apropiación de los leguajes vi-

${ }^{19}$ Ibid., p. 46.

20 David Barsalou se formó con el artista Jerry Kearns en el New York Professional Outreach Program (NYPOP) de 1995-97 en la Universidad de Massachussets en Amherst; es especialista en el estudio de los lenguajes expresivos del cómic.

${ }^{21}$ En David Barsalou, Deconstructing Roy Lichtenstein, en http://www.lifelounge.com.au/artand-design/news/deconstructing-lichtenstein.aspx, octubre 23, 2007. Consultado en septiembre 2011. 
suales y discursos narrativos de estas obras, ya que esta práctica era parte de la propuesta del Pop Art norteamericano: retomar los objetos de consumo visual de la sociedad de masas, darles otro sentido y representar estas escenas de cómics como obras plásticas autónomas, que el artista reprodujo con creatividad en series numeradas. ${ }^{22}$ El director ejecutivo de la Fundación Lichtenstein, Jack Cowart, reitera que Lichtenstein no era un copista: "El trabajo de Roy ha ampliado la formula gráfica y la codificación del sentimiento que fue trabajo por otros dibujantes. La tesis de Barsalou no es precisa, ya que Roy ha cambiado la escala, el color, el tratamiento gráfico y sus implicaciones. No es exactamente una copia". ${ }^{23}$

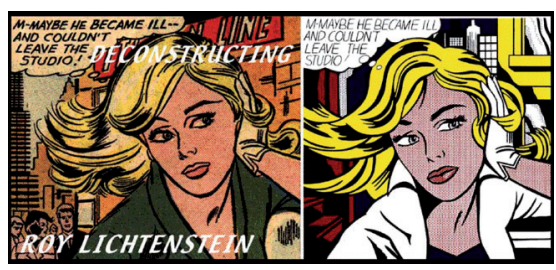

David Barsalou, Deconstructing Roy Lichtenstein, 2000. ${ }^{24}$

En ocasiones estas apropiaciones visuales hacen referencia directa

${ }^{22}$ Por su parte, Barsalou lamenta que los dibujantes de estos cómics originales, entre ellos Joe Kubert, George Tuska, Mike Sekowsky o Jack Kirby no hayan tenido un mayor reconocimiento o crédito por ser los referentes del trabajo plástico de Lichtenstein, véase Barsalou, op.cit.

${ }^{23}$ Idem .

${ }^{24}$ Barsalou, op.cit. al origen icónico de las soluciones estandarizadas o copiadas o se presentan como homenajes a propuestas artísticas originales. ${ }^{25}$

Actualmente hay algunos medios que permiten la libre distribución de copias y versiones modificadas de trabajos previos de otros artistas en diferentes medios, práctica conocida como copyleft. ${ }^{26}$

2. La repetición de la estructura de un producto artístico, diferente del original, pero semejante al mismo: mecanismo de generación de discursos visuales, de repetición del modo narrativo, con la variación estructural en historias análogas (guiones tipo). ${ }^{27}$

${ }^{25}$ Es el caso de las reinterpretaciones plásticas de la obra "Las Meninas" de Diego Velázquez (1656), realizadas por destacados artistas: el grabado de Francisco de Goya (1778), dos obras plásticas de Picasso (1957), la de Salvador Dali (1960), el "Homenaje a Picasso" de Richard Hamilton (1973), la de Joel Peter Witkin 1987, entre las más destacadas.

${ }^{26}$ El copyleft es una práctica al ejercer el derecho de autor que consiste en permitir la libre distribución de copias y versiones modificadas de una obra u otro trabajo, exigiendo que los mismos derechos sean preservados en las versiones modificadas. El término surge en las comunidades de software libre como un juego de palabras en torno a copyright: "derecho de autor", en inglés (literalmente: "derecho de copia"). Se considera que una licencia libre es copyleft cuando además de otorgar permisos de uso, copia, modificación y redistribución de la obra protegida, contiene una cláusula que impone una licencia similar o compatible a las copias y a las obras derivadas.

${ }^{27}$ Calabrese, op.cit., p. 46. 
NOTAS

Un ejemplo de esto es el expuesto por el semiólogo Rocco Mangieri: ${ }^{28}$ en el film Los intocables, Brian de Palma (1987) repite y resignifica el modo narrativo y la estructura visual de la escena en la escalinata del film El acorazado Potemkin de Sergei M. Eisenstein (1925), que reproduce la represión al motín ocurrido en el acorazado Potemkin en 1905, cuando la tripulación se rebeló contra los oficiales del régimen zarista. ${ }^{29} \mathrm{El}$ montaje que utiliza el director soviético se expresa mediante la relación de dos planos yuxtapuestos y resalta su expresividad en el corte, el ritmo, la duración y los encuadres. ${ }^{30}$

En el film norteamericano Los intocables, el montaje narrativo se construye en la tensión de la escena de la escalinata en la estación Central de Chicago. Con la escopeta en mano, Eliot Ness mira el reloj de la estación una y otra vez. A su derecha, una señora llega a la escalinata con una carriola y una maleta, en ese momento se inicia el tiroteo. Varias cámaras

${ }^{28}$ Investigador del Laboratorio de Semiótica del Arte de la Universidad de los Andes, Venezuela; en enero de 2011 impartió en México el seminario "Espacio, tiempo y personaje en la escritura fílmica y cinematografía", en la Universidad Autónoma del Estado de Morelos.

${ }^{29}$ Ver trailer del film El Acorazado Potemkin en $\mathrm{http} / / /$ www.youtube.com/watch?v=GZOFRtmMj8o.

${ }^{30}$ Eisenstein, intérprete de la euforia revolucionaria de la naciente Unión Soviética, advirtió en el cine una fundamentación política. Ver trailer del film Los Intocables en http://www.youtube.com/ watch? $=\operatorname{grd} 8 \mathrm{v}$ VuhIdQ\&noredirect $=1$. reseñan la escena de disparos. En el montaje hay una especial atención en la articulación de las escenas, la dirección de las miradas, las voces, los ruidos, en alternancia con la acción. La escena de Eisenstein ha sido homenajeada por directores famosos en diferentes films por su intensidad expresiva. ${ }^{31}$

3. La repetición para diferentes tipos de consumo: por demanda, para distracción (consolación), reorientado a un consumo productivo; objetos comunicativos que se difunden en diferentes medios masivos -radio, televisión, videos, revistas, cds y dvds-,${ }^{32}$ modos de consumo que se detallan en el siguiente cuadro a partir del estudio de Calabrese: ${ }^{33}$

a. Consumo por b. Distracción c. Reorientado demanda (consolación) (consumo proMadmen Dos tipos de ductivo)

Serie de televi- cuidado The Three Tenors sión creada por Pedro Infante y Termas de CaraMatthew Weiner; Jorge Negrete. calla, Roma, julio inició su trans- Ismael Rodrí- 1990. misión en julio guez, 1952. de 2007.

a. Consumo por demanda. Difunde lo que está en boga y que se comenta en diferentes medios. Un ejemplo es la serie de televisión Madmen creada por Matthew Weiner

${ }^{31}$ Raúl Serra, Críticas, en http://www.notasdecine.es/2098/criticas/critica-los-intocablesde-eliotness/. Consultado en septiembre 2011.

${ }^{32}$ Calabrese, La era neobarroca, op.cit., p. 66.

${ }^{33}$ Ibid., pp. 51-2. 
y protagonizada por Jon Hamm. Producida por Lionsgate Televisión, la serie ha sido aclamada por su autenticidad sobre el desarrollo de la publicidad en la década de los sesentas; la estética de la serie se distingue por el inteligente uso de las sombras y los claroscuros en un estilo visual expresivo y minimalista. La emisión se presentó por primera vez en julio de 2007.

b. Consumo para distracción (consolación). Semana a semana los canales nacionales repiten las películas de la época de oro del cine mexicano, reafirmando emotivamente los imaginarios de la cultura nacional, un ejemplo de esto, entre otros, son las actuaciones de Pedro Infante y Jorge Negrete, en Dos tipos de cuidado, de Ismael Rodríguez, 1952.

c. Consumo reorientado (productivo). En éste resaltan las representaciones mediáticas especiales, homenajes y eventos culturales, con contenidos atractivos para atraer a nuevos receptores. Un ejemplo de esto han sido las actuaciones del tenor italiano que realizó con los españoles Plácido Domingo y José Carreras, con quienes formó el trío The Three Tenors. Esta idea fue propuesta por Pavarotti para hacer llegar il bel canto a todos los públicos, e inició con un concierto en las Termas de Caracalla en Roma con motivo de la clausura del mundial de fútbol de 1990. El éxito fue tan resonante que se repitió en las clausuras de los suce- sivos mundiales de 1994, 1998 y $2002 .{ }^{34}$ Este espectáculo en un ejemplo del remix mediático de la alta cultura con la popular.

\section{Conclusiones}

Las preguntas que formula el semiólogo frente a esta descripción de la repetición mediática son puntuales: ¿qué tanto resulta original el hipertexto producto de una estética de la repetición? ¿Hasta dónde su concepto, su diseño y su recepción sólo pueden estar modelados por estas estrategias y formas de la repetición actual? ${ }^{35}$

De esta manera, se pone en evidencia que en la estética de la repetición la originalidad no es más que la capacidad de variar, descentrar o deformar fórmulas preestablecidas. La minúscula variante es la que producirá el placer del discurso visual y, por eso, la capacidad para ejecutar variantes resulta sobrevalorada. Las competencias requeridas en la

${ }^{34}$ Durante varios años seguidos a partir de 1991, Pavarotti respondió a la solicitud de la organización War Child para recaudar fondos para la construcción de un centro de musicoterapia. De esta forma, anualmente se realizaron conciertos en la ciudad de Módena bajo el título Luciano Pavarotti \& friends, donde se presentaba él junto con reconocidos músicos para recaudar fondos que apoyaban diferentes causas. De estos espectáculos, la repetición se amplió en transmisiones televisivas, dvd, videos y sitios web.

${ }^{35}$ Ibid., p. 62. 
NOTAS

pragmática del emisor-cuyo trabajo consiste en la construcción de modelos para armar-, en propuestas de estructuras flexibles para crear narrativas prefabricadas y promover el goce y el juego. ${ }^{36}$

El virtuosismo del autor contemporáneo reside en el rebuscamiento de efectos variados, lo que termina empobreciendo una competencia anterior ligada a la estética de la singularidad, en donde predominaba el virtuosismo de crear verdaderas historias, llenas de tramas y de intrigas, cargadas de simbolismo y lecciones. ${ }^{37}$
Calabrese explica sobre esta reiteración de temas y motivos, aceptada por creadores y receptores de la nueva estética, que surge por una especie de reacción al exceso de historia, al exceso de lo dicho, el exceso de fórmulas y representaciones. ${ }^{38}$ Esta saturación de las representaciones deshace la idea de la secuencialidad en las manifestaciones históricas, en los modelos morfológicos artísticos y mediáticos; y se dirige a la repetición de lo fragmentario y del detalle, en la extensión de sus límites, en el exceso y la metamorfosis, en la producción de enunciados ficcionales y en la ambigüedad de su recepción estética. 